\title{
Phenotype and Function of Murine Peritoneal Cavity Macrophage Derived-Dendritic Cells
}

\author{
Levi H. C. MAKALA ${ }^{1)}$, Yoshifumi NISHIKAWA ${ }^{1)}$, Masayuki MISHIMA ${ }^{1)}$, Noboru INOUE ${ }^{1)}$, Xuenan XUAN ${ }^{1)}$, \\ Hiroshi SUZUKI ${ }^{1)}$, Kozo FUJISAKI ${ }^{1)}$, Takeshi MIKAMI ${ }^{1)}$ and Hideyuki NAGASAWA ${ }^{1) *}$ \\ ${ }^{1)}$ National Research Center for Protozoan Diseases, Obihiro University of Agriculture and Veterinary Medicine, Inada-Cho, Obihiro, \\ Hokkaido 080-8555, Japan
}

(Received 6 February 2002/Accepted 21 May 2002)

ABSTRACT. The accessory activity was reported in murine peritoneal cavity macrophage derived dendritic cells (PEC-DC) in a mixed lymphocyte reaction (MLR). Here we continue the characterization of the generated PEC-DC using the criteria of morphology, phenotype and other accessory function. We have demonstrated that murine peritoneal cavity macrophages can be induced to differentiate in vitro into cells exhibiting typical dendritic cell (DC) morphology, phenotype and function. The proliferative capacity of the progenitors was amplified in the first step of the culture (day 0-7) using a combination of early cytokines: interleukin 4 and granulocyte-macrophage colony-stimulating factor. The second step of the culture started at day 7 with the removal of early growth factors to allow differentiation and final maturation of DC during 2 days of culture with interferon gamma plus either Toxoplasma lysate antigen (TLA) or lipopol ysaccharide (LPS), a bacterial agent as a DC maturing agent. The resulting DC population exhibited typical DC morphology and expressed higher levels of MHC class II and the co-stimulatory molecules CD80 and CD86 compared to the untreated peritoneal cells. The generated DC cells efficiently presented soluble protein antigen to $\mathrm{CD}^{+}$spleen $\mathrm{T}$ cells.

KEY WORDS: differentiation, growth factor, peritoneal cavity macrophage-derived dendritic cell, progenitor.

J. Vet. Med. Sci. 64(9): 813-820, 2002

Dendritic cells (DC) constitute a polymorphic leukocyte population of antigen presenting cells (APC) linking the innate immune system with the adaptive specific immune system. They are able to activate naive $\mathrm{T}$ cells and generate primary $\mathrm{T}$ cell responses [3, 24, 26, 27, 47]. Isolation of DC is difficult because of their low numbers in tissues and consequently, studies have been hampered by low yield following purification $[24,26,27,38,44]$. Despite the central role played by DC in immune regulation and antigen presentation, little is known about their differentiation pathway [25, $34,36,48]$. More studies in this regard need to be carried out.

Several groups have succeeded in generating large numbers of functional DC from their proliferating progenitors located in bone marrow, spleen or blood in the presence of appropriate cytokines $[1,4,6,8,14,16,18,22,23,30]$. Other studies also suggest that monocytes can differentiate into macrophages or DC $[9,19,34,40]$. It is now abundantly clear that DC can be generated from circulating monocytes/macrophages [3,8], alveolar and pleural macrophages [40] in in vitro cultures in the presence of a variety of cytokines. Recently, Rezzani et al. [36] reported that resting peritoneal cells in the mouse represent an immature population, capable of further differentiation along either the DC or the macrophagic pathway using granulocyte macrophage colony stimulating factor (GM-CSF) alone or in combination with tumor necrosis factor-alpha (TNF- $\alpha$ ). However, the ability of GM-CSF alone has been shown to

\footnotetext{
* Correspondence to: Prof. Nagasawa H., National Research Center for Protozoan Diseases, Obihiro University of Agriculture and Veterinary Medicine, Inada-cho, Obihiro, Hokkaido 0808555, Japan.
}

be very limited in obtaining large numbers of cells [16]. Among the cytokines most commonly used to generate myeloid DC, GM-CSF plays a critical role and interleukin 4 (IL-4) has been shown to facilitate the differentiation of the macrophages into CD14-/CD1a+ DC lineage [1]. In all these studies, macrophage derived DC have not only efficiently stimulated lymphocytes in mixed lymphocyte reaction, but also primed $\mathrm{T}$ cells in vitro and in vivo, in an antigen-specific manner. Other studies have also shown that DC generated in GM-CSF alone, as well as in GM-CSF plus IL-4, can prime antigen specific $\mathrm{T}$ cells in vivo and in vitro $[32,33]$. These findings and also the fact that most experimental protocols devised to study in vivo and in vitro immunological responses, biological analysis of DC function, biochemical studies and molecular mechanisms involved in antigen processing and presentation, require large cell numbers $\left(10^{8}-10^{9}\right)$, prompted us to investigate the potentiality of peritoneal cavity macrophages to differentiate into DC in the presence of GM-CSF plus IL-4. Our investigations show that culturing of resting peritoneal macrophages in GM-CSF plus IL-4 followed by further maturation in interferon-gamma (IFN- $\gamma$ ) plus lipopolysaccharide (LPS), gives rise to a population of DC that is functional.

\section{MATERIALS AND METHODS}

Animals, culture medium and reagents: Samples were obtained from BALB/c mice from a commercial supplier (CLEA, Japan, Inc.). All experimental mice 6-10 weeks of age and both sexes were maintained in conventional conditions on a commercial diet (CLEA, Japan, Inc.). Except where stated, all cell manipulations were carried out at room 
temperature in Hank's balanced salt solution (HBSS) without calcium or magnesium (Flow Labs, Irvine, UK), buffered with $5 \mathrm{mM}$ HEPES and $0.4 \mathrm{~g} / \mathrm{l}$ sodium bicarbonate. Tissue culture medium was RPMI-1640 (Dutch modification, Gibco, Paisley, UK) supplemented with $2 \mathrm{mM} \mathrm{L-}$ glutamine; $1 \mathrm{mM}$ sodium pyruvate (Flow labs, Irvine, UK); $40 \mathrm{~g} / \mathrm{m} l$ gentamicin; $100 \mathrm{IU} / \mathrm{m} l$ penicillin; $100 \mu \mathrm{g} / \mathrm{m} l$ streptomycin; $10 \%$ fetal bovine serum (FBS); and $10 \mu \mathrm{M} 2$-mercaptoethanol (2-ME)(Sigma, Poole, Dorset, UK) unless otherwise stated. The following cytokines and antibodies were used: murine recombinant GM-CSF (Sigma); murine recombinant IFN- $\gamma$ (Sigma); murine recombinant IL-4 (Sigma); anti-murine recombinant IFN- $\gamma$ (Sigma); and antimurine recombinant IL-4 (Sigma). The following labeled anti-mouse monoclonal antibodies specific for macrophages, DC and T cells used were: anti-CD11c PE (HL3) [31]; anti-DEC-205 FITC (NLDC-145) [17]; anti-MHC class II (I-A ${ }^{\text {b }) ~ F I T C ~(A F 6-120.1) ~[45] ; ~ a n t i-C D 80 ~ F I T C ~(B 7-1) ~}$ [35]; anti-CD86 FITC (B7-2) [11]; anti-CD11b (Mac-1) FITC (M1/70) [39] (Pharmingen International, U.S.A.); anti-CD34 FITC (MEC 14.7) [12]: and anti-F4/80 FITC (C1:A3-1) [2] (Serotec Ltd., Oxford, U.K.). The anti-MHC class II (anti-mouse I- $\mathrm{A}^{\mathrm{b}}\left(\mathrm{A}_{\alpha}^{\mathrm{b}}\right)(\mathrm{AF} 6-120.1)$ used in this study reacts with the $\alpha$ chain of the I-A ${ }^{\mathrm{b}}$ MHC class II alloantigen, and cross reacts with cells from mice of the $\mathrm{H}-2^{\mathrm{K}}$, $\mathrm{H}-2^{\mathrm{p}}$ and $\mathrm{H}-2^{\mathrm{u}}$ haplotypes which cover the mice types used in our study. All experiments using animals were carried out in accordance with rules and ordinances of the National Research Center for Protozoan Diseases, Obihiro University of Agriculture and Veterinary Medicine, and are in line with acceptable international standards.

Immunizations: Mice were immunized with $0.2 \mathrm{mg}$ of the RH strain of $T$. gondii homogenate. The animals were injected intra-peritoneally and were boosted 3 to 4 times at intervals of 7 days with the same dose of homogenate in PBS or culture medium. Splenocytes purified for $\mathrm{CD}^{+} \mathrm{T}$ cells were isolated 5-10 days after the last boost.

Peritoneal macrophage and dendritic cell generation: Peritoneal cavity macrophages (PEC-MФ) and peritoneal cavity macrophage-derived DC (PEC-DC), were isolated according a previously described method by Makala et al. [27]. Briefly, a peritoneal cavity lavage was carried out, by flushing through the peritoneum with $5 \mathrm{ml}$ of sterile PBS. Lavage cells were washed twice for $5 \mathrm{~min}$ at $400 \mathrm{~g}$ and at $4^{\circ} \mathrm{C}$ in HBSS and re-suspended in tissue culture medium. Erythrocytes were removed by osmotic lysis with ammonium chloride solution, followed by a further wash for $5 \mathrm{~min}$ at $400 \mathrm{~g}$ and at $4^{\circ} \mathrm{C}$ then plated in $35 \mathrm{~mm}$ petri dishes (Costar Corp., Cambridge, Mass. U.S.A.) at a density of $2 \times 10^{5}$ cells/m $l$ in RPMI-1640 supplemented with $10 \%$ FBS. Cells were diluted enough to avoid overlapping of cells in layers during the adherence incubation for $2 \mathrm{hr}$ at $37^{\circ} \mathrm{C}, 5 \% \mathrm{CO}_{2}$. Non-adherent cells were then discarded, and fresh medium added. The adherent cells were referred to as peritoneal cavity macrophages (PEC-M $\Phi)$. The purity of PEC-M $\Phi$ as determined by flow cytometry using macrophage specific markers, anti-Mac-1 (CD11b) [39] and anti-F4/80 [2] was always greater than $90 \%$. In three different experiments, the adherent cells were cultured in 4-6 $\mathrm{m} l$ culture medium with or without growth factors $(1,000 \mathrm{U} / \mathrm{m} l \mathrm{GM}-\mathrm{CSF}$ and 1,000 $\mathrm{U} / \mathrm{m} l$ IL-4) for 7 days. Non-adherent cells and loosely adherent cells were harvested by moderately vigorous aspiration. The harvested DC were re-suspended in new culture medium and further cultured with $250 \mathrm{U} / \mathrm{m} l \mathrm{IFN}-\gamma$ plus 1 $\mu \mathrm{g} / \mathrm{m} l$ LPS for $48 \mathrm{hr}$ to mature them further. These were referred to as the PEC-DC. The purity of PEC-DC as determined by flow cytometry using the DC specific markers, DEC-205 [17, 20] and CD11c [31] was always greater than $90 \%$.

In some experiments, GM-CSF plus IL-4 were pre-incubated with different concentrations of blocking anti-murine recombinant GM-CSF (Sigma); and anti-murine recombinant IL-4 (Sigma) $\mathrm{mAb}$ for $1 \mathrm{hr}$ at $37^{\circ} \mathrm{C}$, before culture administration.

In three different experiments, peritoneal macrophages were seeded in six-well plates treated with or without GMCSF. Cells were harvested on a daily basis from each single well and their viability checked by trypan blue exclusion, counting a total of 200 cells. In separate investigations following detachment of cells after adherence, limiting dilution assays were performed seeding a total of 1500 cells in 96well plates at one cell/well concentration. These were incubated for 7 days in culture medium with or without GM-CSF and the cells harvested. The resulting cells were tested for viability and used for immunocytochemical detection of DEC-205 (NLDC-145) by peroxidase anti-peroxidase staining as previously described [20].

Isolation of $\mathrm{CD} 3+\mathrm{T}$ cells: Spleens cells purified for $\mathrm{CD} 3$ were isolated using a method described by Makala et al. [27]. Briefly, allogeneic mice spleens were aseptically excised, placed in a petridish to dissect away the serosa and fat, then cut into smaller pieces. This was followed by centrifugation of the cell suspension for $5 \mathrm{~min}$ at $4^{\circ} \mathrm{C}$ and at 600 g. In some cases $0.83 \%$ ammonium chloride was used to lyse red blood cells. Lymphocytes purified for CD3+ T cells were isolated from resulting mouse spleen leukocyte cell population using a Cellect mouse $\mathrm{T}$ cell kit (Cytovax Biotechnologies, Canada) as per manufacturer's instructions. The purity of the isolated cells from the Cellect mouse $\mathrm{T}$ cell kit as determined by flow cytometry using anti-CD3 mAb was always greater than $90 \%$.

Electron microscopy: For ultrastructural observations, 1 $\times 10^{6}$ cells were centrifuged at $400 \mathrm{~g}$ for $10 \mathrm{~min}$, pelleted and fixed overnight at $40^{\circ} \mathrm{C}$ in $2.5 \%$ glutaraldehyde in $0.1 \mathrm{M}$ cacodylate buffer for $1 \mathrm{hr}$, rinsed in buffer, post-fixed in $2 \%$ osmium tetroxide in $0.2 \mathrm{M}$ cacodylate buffer for $1 \mathrm{hr}$, dehydrated through a graded alcohol series and finally embeded in TAAB Epon 812 low viscosity resin. Ultra-thin sections (70 $\mathrm{nm}$ ) were cut using a diamond knife, grid stained with $1 \%$ uranyl acetate and lead citrate and examined using a Hitachi transmission electron microscope (TEM) (Hitachi Ltd., Tokyo, Japan).

Flow cytometry: Surface antigen expression of CD11c, DEC-205, CD34, MHC class II antigens, CD80, CD86, 
CD11b (Mac-1) and F4/80 was measured on cytokine treated and untreated samples by flow cytometry. $2 \times 10^{5}$ cells/sample were washed once in PBS containing 5\% FBS and $0.02 \% \mathrm{NaN}_{3}$ for $1 \mathrm{~min}$ at $400 \mathrm{~g}$. Binding was visualized with a single step technique involving incubation with $5 \mu \mathrm{l}$ of the following labeled anti-mouse mAb anti-CD11c PE (HL3); anti-DEC-205 FITC (NLDC-145); anti-MHC class

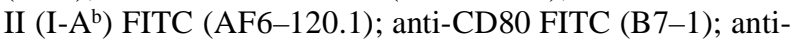
CD86 FITC (B7-2); anti-CD11b (Mac-1) FITC (M1/70) (Pharmingen International, U.S.A.); anti-CD34 FITC (MEC 14.7): and anti-F4/80 FITC (C1:A3-1) (Serotec Ltd., Oxford, U.K.). After incubation cells were washed, analyzed and fluorescence quantified using a Coulter EPICSXL flow cytometer at $488 \mathrm{~nm}$. Cells were electronically gated on forward angle light scatter to exclude debri and on $90^{\circ}$ light scatter to exclude granulocytes.

Antigen presentation assay: Lymphocytes were purified from spleens of mice previously immunized with $T$. gondii homogenate using the Cellect mouse $\mathrm{T}$ cell Kit (Cytovax Biotechnologies, Edmonton, Alberta, Canada). Peritoneal macrophage-derived DC, were additionally prepared from these mice. Cultures were established in 96 well flat-bottomed tissue culture plates (Falcon). Individual wells contained $2 \times 10^{5} \mathrm{CD} 3+$ spleen $\mathrm{T}$ cells together with a range of concentrations of irradiated peritoneal macrophage-derived DC with or without TLA in a total volume of $100 \mu l$. Responder CD3+ spleen $\mathrm{T}$ cells were cultured with a range of concentrations of the generated DC to give final responder/stimulator ratios of 1:1,10:1 and 100:1. Control cultures were arranged as follows: responder CD3+ spleen $\mathrm{T}$ cells alone or with TLA; unfractionated spleen cells alone or with TLA; and stimulator peritoneal macrophage-derived DC alone or with TLA. Cultures were established in triplicate wells. Cultures were incubated at $37^{\circ} \mathrm{C}$ in $95 \%$ air, $5 \%$ $\mathrm{CO}_{2}$ for 48,72 and $96 \mathrm{hr}$. Four hours before the termination of cultures, cells were pulsed with a non-radio active cell counting kit-8 (Dojindo, Japan). Cells were then harvested and using an ELISA reader (Corona Electric, Japan) absorbance was determined at $450 \mathrm{~nm}$.

Statistical analysis: Statistical analysis of the results of the mixed lymphocyte reaction and antigen presentation assays were carried out as a matrix of pair-wise comparisons probabilities $(\mathrm{P})$ in multiple analysis of variance.

\section{RESULTS}

The characterization of the generated GM-CSF (or IL-4) treated PEC-MФ was carried out using the criteria of morphology, phenotype and accessory function.

Yield, purity and viability of peritoneal macrophagederived dendritic cells: The yield of cell populations routinely isolated from the peritoneal cavity of 10-12 mice after osmotic lysis of red blood cells ranged from $1 \times 10^{8}$ $1.3 \times 10^{8}$. After plastic adherence the number of resting peritoneal cells was approximately $1 \times 10^{7}-3 \times 10^{7}$. Upon treatment with $1,000 \mathrm{U} / \mathrm{m} l$ GM-CSF and $1,000 \mathrm{U} / \mathrm{m} l \mathrm{IL}-4$ for 7 days, recovery of PEC macrophage derived-DC ranged from $3-5 \times 10^{8}$. The purity of PEC-DC as determined by flow cytometry using the DC specific markers, DEC-205 $[17,20]$ and CD11c [31] was always greater than $90 \%$. Viability of the cells as determined by trypan blue was always greater than $90 \%$.

Morphology of peritoneal macrophage-derived dendritic cells: Using the criteria of relative size, cytoplasm/nucleus ratio, shape and position of nucleus, and cytoplasmic protuberances/dendrites cells were characterized under light and electron microscope. The cell appeared round shaped by both light electron microscopy and remained unchanged morphologically during incubation in the absence of growth factors (data not shown). Following treatment with 1,000 $\mathrm{U} / \mathrm{m} l$ GM-CSF and 1,000 U/m $l$ IL-4, many cells showed evidence of cytoplasmic protrusions, a typical characteristic of DC. These cells were observed to continually extend, retract and re-orientate their processes or veils in live cultures when observed over a long period of time (data not shown). Ultrastructural investigations provided further evidence of typical DC characteristics, such as the above mentioned cytoplasmic veils, irregulary-shaped excentric nuclei, autophagosomes and multivesicular bodies (Fig. 1). No Birbeck granules a characteristic morphological marker of the Langerhan's cells, could be detected.

Expression of surface membrane antigens: Mouse peritoneal cells were examined for expression of specific DC surface membrane antigens $[31,17]$ antigens important for
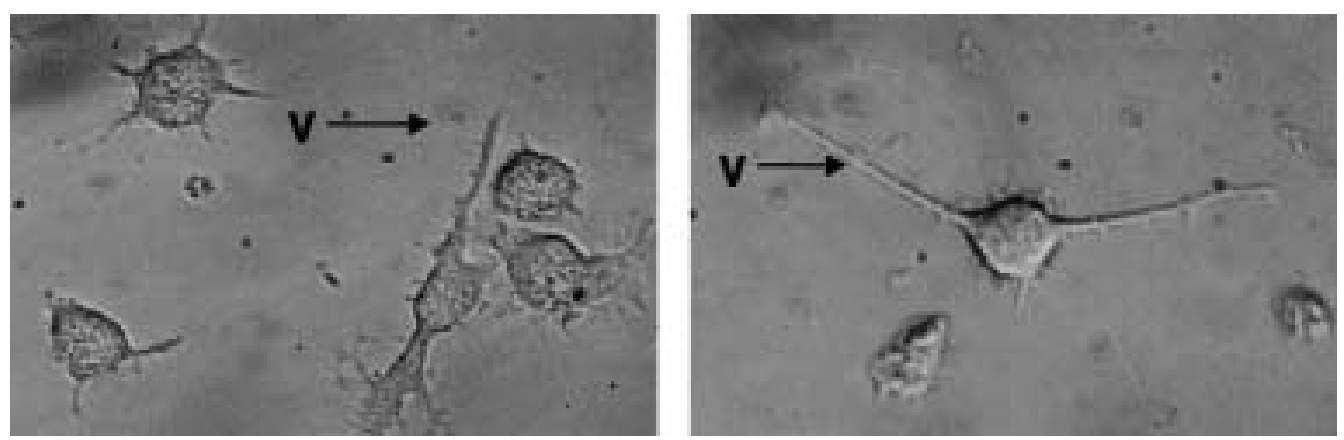

Fig. 1. Light microscopic visualization of peritoneal cavity macrophage-derived dendritic cells (DC) exhibiting typical DC morphology. Note the irregular shape and the typical cytoplasmic protuberances/veils $(V) .(\times 670)$. 
Table 1. Phenotypic analysis of peritoneal cells, at days, 0 or 7 of culture in the presence or absence (control) of 1,000 U/m $l$ GM-CSF plus $1,000 \mathrm{U} / \mathrm{m} l \mathrm{IL}-4$

\begin{tabular}{lrcc}
\hline Antigen & \multicolumn{1}{c}{ Day 0 } & Day 7 (control) & Day 7 GM-CSF+ IL-4 \\
\hline CD11c & $1.4 \pm 0.4$ & $3.0 \pm 0.8$ & $92.5 \pm 5.4$ \\
DEC-205 & $5.7 \pm 1.2$ & $6.9 \pm 2.3$ & $95.7 \pm 6.1$ \\
CD80 (B7-1) & $38.9 \pm 2.7$ & $69.5 \pm 3.4$ & $97.3 \pm 6.9$ \\
CD86 (B7-2) & $8.9 \pm 3.6$ & $19.6 \pm 6.5$ & $92.5 \pm 8.9$ \\
MHC class II & $9.8 \pm 0.7$ & $78.5 \pm 5.4$ & $98.5 \pm 0.6$ \\
F4/80 & $91.0 \pm 1.7$ & $93.8 \pm 3.0$ & $99.7 \pm 1.4$ \\
CD11b (Mac-1) & $90.0 \pm 1.8$ & $91.0 \pm 1.5$ & $98.7 \pm 0.8$ \\
CD34 & $0.06 \pm 4.4$ & $0.9 \pm 1.9$ & $0.77 \pm 3.9$ \\
\hline
\end{tabular}

Note - Data are expressed as mean percentages of three independent experiments plus or minus standard deviation $( \pm S D)$.

APC/ T cell interactions $[11,35,45]$ and macrophage specific markers [2, 17, 39], either immediately after plastic adherence (day 0) or after 7 days of culture in the presence or absence of 1,000 U/m $l$ GM-CSF + IL-4 (Table 1). The starting peritoneal cell population showed a high expression of the macrophage markers F4/80 and CD11b (Mac-1) and a virtually absent expression of CD34 (Table 1), a marker typical of haemopoietic progenitors [12]. Cells cultured for 7 days in the absence of growth factors exhibited low or no expression for DC markers CD11c and DEC-205. In contrast, over $90 \%$ of the GM-CSF + IL-4 treated peritoneal cells expressed the DC markers. Moreover, the GM-CSF + IL-4 treated cells showed an up-regulated expression of MHC class II and the co-stimulatory molecules CD80 and CD86 (Table 1). Pre-incubation of GM-CSF plus IL-4 with $75 \mu \mathrm{g} / \mathrm{m} l$ of anti-GM-CSF and IL-4 blocking mAbs completely inhibited the ability of the growth factor combination to drive the phenotypic differentiation of mouse peritoneal cells into DC (data not shown). In order to ascertain that the majority of the starting adherent population differentiated into DC, a single cell assay was performed. Virtually all the cells stained positive for the DC marker DEC-205 (NLDC145).

It was also possible to demonstrate that IL-4 was able to facilitate DC differentiation of peritoneal cavity macrophages, especially when used in combination with GM-CSF (data not shown).

Antigen presentation by peritoneal macrophage derived dendritic cells: $\mathrm{CD} 3+$ spleen $\mathrm{T}$ cells from mice that were previously immunized with $T$. gondii homogenate were cocultured with PEC-DC, with or without TLA over a range of effector/ target ratios. The results of the assessment of the effectiveness of PEC-DC to trigger TLA-driven responses are summarized in Fig. 3. Data were pooled between each experiment and multiple analyses of variance applied. Proliferative responses at a 1:1 responder:stimulator ratio were significantly greater than responses at 1:10 and 1:100 $(\mathrm{P}<0.0004)$. In vitro irradiation of $\mathrm{PEC}-\mathrm{DC}$ did not alter their capacity to act as accessory cells.

As shown in Fig. 3, the magnitude of the proliferative responses increased with time and responder:stimulator ratio. Moreover, CD3+ spleen $\mathrm{T}$ cells from cultures com- prising 1:1 and 10:1 ratios showed significant proliferation compared to control cultures $(\mathrm{P}<0.005)$. CD3+ spleen $\mathrm{T}$ cells from cultures comprising 100:1 did not proliferate significantly $(\mathrm{P}>0.5)$.

\section{DISCUSSION}

We have isolated a highly MHC class II positive PEC macrophage derived-DC in high purity using growth factors using a two step culture system. This culture system has the potential to produce $3-5 \times 10^{8}$ cells following a peritoneal lavage of 10-12 mice. Characterization of the generated cells by morphology, surface antigens and accessory function suggests that these cells are DC. These data compare well with that of Lutz et al. [23], who reported the growth of $1-3 \times 10^{8}$ DC from the bone marrow of a single mouse using a modified technique of Inaba et al. [16]. Recently, Rezzani et al. [36] described the generation of DC-like cells using either GM-CSF alone or in combination with TNF- $\alpha$. In a series of experiments, the authors demonstrated that TNF- $\alpha$ did not appear to be essential for the induction of DC differentiation. The findings of Rezzani et al. [36] are in agreement with previous data of Caux et al. [7], in which it was shown that only GM-CSF alone was required for the terminal differentiation of intermediate DC to mature DC. However, the ability of GM-CSF alone in the early stages of differentiation to grow DC has been shown to be very limited as Lu et al. [22] demonstrated when he obtained $1.5 \times$ $10^{6} \mathrm{DC}$ from an entire spleen. While, Rezzani et al. [36] showed that murine peritoneal cavity macrophages are DC progenitors consistent with our findings, we went on further to investigate the influence of the early cytokine, IL-4 known to amplify the proliferation of myeloid progenitors in synergy with GM-CSF, thereby, increasing the yield of the generated DC from PEC-M $\phi$ greatly. The present data appear to be inconsistent with the former findings of Rezzani et al. [36], which demonstrated that once peritoneal cells were committed to the macrophage lineage, they lost their ability to differentiate into DC. The view that DC generated from myeloid precursors belong to a lineage separate from macrophages/ monocytes persists, ignoring the fact that macrophages as well as DC share all the machinery 

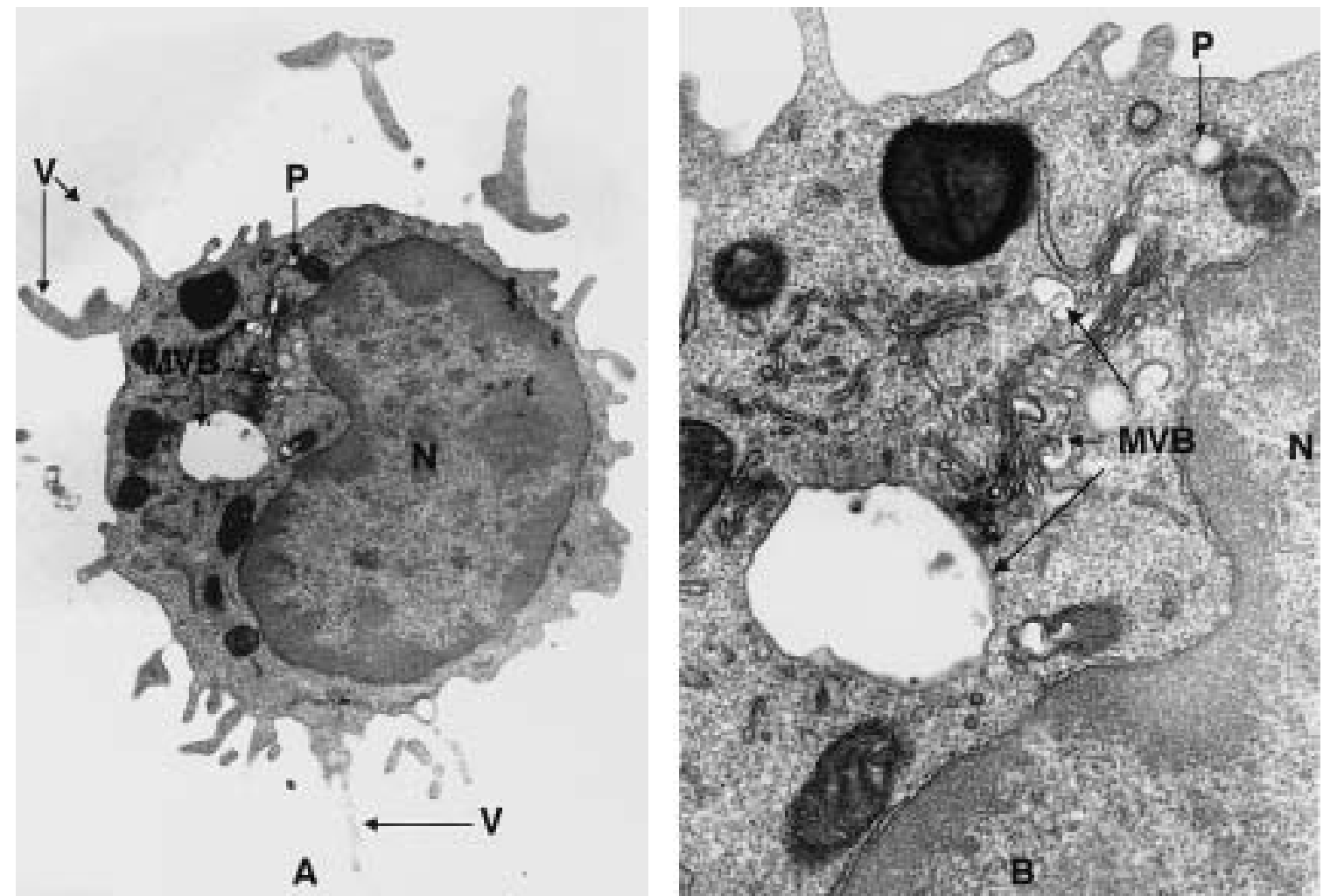

Fig. 2. Transmission electron microscopic visualization of peritoneal cavity macrophage-derived dendritic cells (DC) exhibiting typical DC morphology. Note the irregularly shaped nuclei (N), multi-vesicular bodies (MVB) and the typical cytoplasmic protuberances/veils $(\mathrm{V})$ and autophagosomes $(\mathrm{P}) . \mathrm{A}(\times 7,000)$ and $\mathrm{B}(\times 20,000)$.

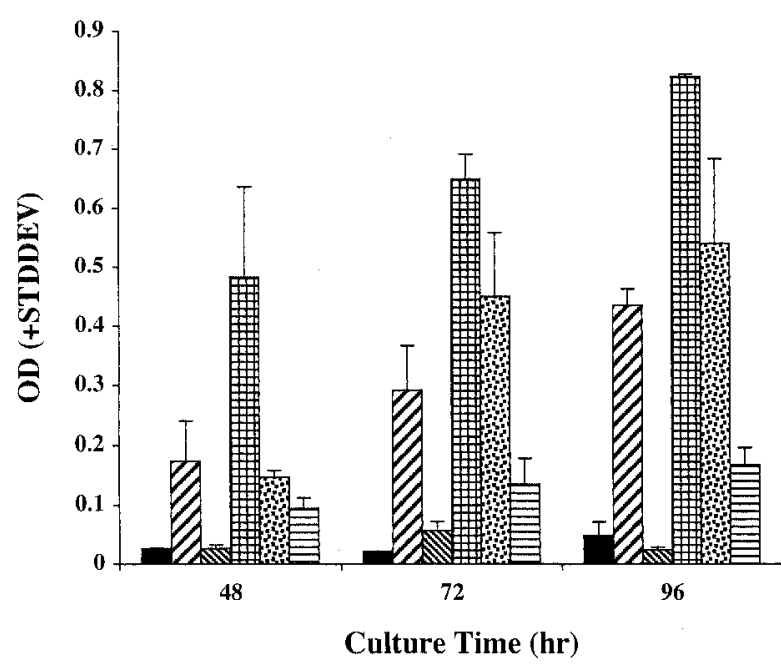

Fig. 3. Proliferative response of immune $\mathrm{CD}^{+}$spleen $\mathrm{T}$ cells after Toxoplasma lysate antigen (TLA) presentation by peritoneal cavity macrophage-derived dendritic cells (PEC-DC). Bars represent mean OD from triplicate wells plus standard deviations $(+\mathrm{SD})$.

$\square \mathrm{CD} 3{ }^{+} \mathrm{T}$ cells

YCD3 ${ }^{+} \mathrm{T}$ cells + PEC-DC

$\mathbb{C D} 3+T$ cells + TLA

⿷CD3 ${ }^{+} \mathrm{T}$ cells + PEC-DC + TLA $(1: 1)$

다은 + T cells + PEC-DC + TLA $(10: 1)$

䀾CD3 ${ }^{+} \mathrm{T}$ cells + PEC-DC + TLA (100:1) needed for antigen capture, uptake processing and presentation. From this perspective, it is not at all difficult to appreciate how then macrophage-derived APC can create a cytokine microenvironment and differentiate into accessory cells that facilitate $\mathrm{T}$ cell activation and tolerance, that is, non-responsiveness and or inhibition of responses. Macrophages are versatile immunocytes. Their role in physiology includes phagocytic clearance of undesirable cells plus macromolecules, initiation of inflammation, effector functions, for example, cytotoxicity as well as antibody dependent cellular cytotoxicity, and orchestration of the generation of $\mathrm{T}$ cell mediated immunity through antigen presentation. As such, macrophages need to go through different routes of maturation or differentiation so as to carry out this diverse array of functions. In contrast, while DC are non-phagocytic they have high endocytic levels enabling them to take up antigens using distinct mechanisms, for example, macropinocytosis and receptor mediated endocytosis, making them the most efficient antigen presenting cells.

Our findings are consistent with those of other studies, which suggest that both mature macrophages and blood monocytes could differentiate to DC $[3,8,40]$. The results of this study may also offer an explanation for previous in vivo studies that describe the presence of DC in human [5], rat [42], and mouse [29] peritoneal cavities. In earlier studies, De Baker et al. [10], Wijffels et al. [46] and Leenen et 
al. [21] also showed that the mouse peritoneum contains precursors of cells belonging to the mononuclear phagocytic system. It is most likely therefore, that the mouse peritoneum represents a potential site of $\mathrm{M} \Phi$ and DC differentiation. Our findings suggest that our generated cells are of myeloid origin as evidenced by the low or virtually no expression of CD34, a marker typical of haemopoietic progenitors [12].

The present study clearly shows that peritoneal macrophages are highly proliferating progenitors for functional DC, and that the growth potential of these cells is worthy of precise investigation using defined recombinant growth factors. The data presented in this paper represents the first evidence that murine peritoneal cavity macrophages can differentiate into DC following incubation with GM-CSF plus IL-4 with an additional maturation step in IFN- $\gamma$ plus LPS. The fact that macrophages as well as DC share all the machinery needed for antigen capture, processing and presentation perhaps may help appreciate why the PEC-DC can differentiate into accessory cells capable of facilitating $\mathrm{T}$ cell responses or even their inhibition. The ability of peritoneal macrophages to differentiate into DC is in agreement with the current model of DC differentiation, which considers DC to have a myeloid origin, which most likely branches off from the myelopoietic lineage during early or later stages of the differentiation pathway [34]. Recently, it has been reported that common lymphoid progenitors can also generate DC [28]. The observation that PEC macrophage derived-DC express the macrophage specific marker F4/80 [37], suggests a lineage relationship with macrophages and monocytes. However, recent studies have demonstrated that F4/ 80 is no longer considered a specific macrophage marker, as some DC subsets express this molecule [13, 43]. The generated cells in this study expressed very high levels of F4/80.

It is likely that, the progenitor PEC-M $\Phi$, as well as the generated PEC-DC have a distinct biological function. This function may have been affected by the long isolation procedure, which involved incubation with growth factors and maturing agents and may possibly have resulted in either activation of the cells or down regulation of biological functions (e.g. antigen presentation, as well a possible loss of some surface antigens/markers). All the mentioned factors may have had an effect on the biological function of the cells. However, in our previous work [27] we showed that allogeneic responses initiated in vitro by PEC macrophage derived-DC, were of high magnitude demonstrating that the isolated cells have a potent MLR activity, consistent with their predicted activity as DC [27]. The results of this study agree with previous reports that have demonstrated the stimulatory capacity of DC generated from murine or rat bone marrow blood and spleen [4, 8, 22, 41, 48]. Additionally, we have also demonstrated in the present study that the isolated PEC-DC, were able to maintain a protein binding function as is expected of functional APC. Thus the ability to bind, process and present antigen as well as maintenance of high MHC class II antigen expression and activation of $\mathrm{T}$ cells probably the most essential criteria regarding APC were all met by the isolated PEC-DC in our experiments. This is not a surprising result given the reported capacity of DC for antigen presentation in other systems in vitro and in vivo [15]. Our results also suggest that the generated PECDC may have a mature antigen processing enzyme profile, pointing to their enhanced capacity to process antigen in vitro.

In conclusion, the present data has shown that early cytokines, IL-4 and GM-CSF combined with IFN- $\gamma$ and LPS are highly effective in inducing the proliferation of murine PEC macrophages derived-DC progenitors in vitro. These cells are able to differentiate into fully functional mature DC after 11 days of culture, thus emphasizing the hypothesis that DC most likely branched off the myelopoietic lineage rather than the haemopoietic pathway during either early or later stages in their ontogeny. Moreover, these cells can be further purified to homogeneity and used to study molecular endocytotis mechanisms as well as in vivo and in vitro immunological responses and might be a useful source of DC for immunotherapy.

ACKNOWLEDGEMENTS. We are indebted to the Japanese Society for the Promotion of Science (JSPS) for financial support. The first author is supported by a JSPS research fellowship for young scientists.

\section{REFERENCES}

1. Araki, H., Katayama, N., Mitani, H., Suzuki, H., Nishikawa, H., Masuya, M., Ikuta, Y., Hoshino, N., Miyashita, H., Nishii, K., Minami, N. and Shiku, H. 2001. Efficient ex vivo generation of dendritic cells from CD14+ blood monocytes in the presence of human serum albumin for use in clinical vaccine trials. Br. J. Haematol. 114: 681-689.

2. Austyn, J. M., Kupiec-weghuski, J. W., Hawkins, D. F. and Morris, P.J. 1988. Migration patterns of DC in the mouse. Homing to $\mathrm{T}$ cell-dependent areas of spleen, and binding within marginal zones. J. Exp. Med. 167: 646-651.

3. Banchereau, J. and Steinman, R. M. 1998. Dendritic cells and control of immunity. Nature (Lond.) 392: 245-252.

4. Berthier, R., Martinon-Ego, C., Laharie, A. M. and Marche, P. N. 2000. A two-step culture method starting with early growth factors permits enhanced production of functional dendritic cells from murine splenocytes. J. Immunol. Methods 239: 95107.

5. Betjes, M. G., Tuk, C. W., Struijk, D. G., Krediet, R. T., Arisz, L. and Beelen, R. H. 1993. Antigen-presenting capacity of macrophages and dendritic cells in the peritoneal cavity of patients treated with peritoneal dialysis. Clin. Ex. Immunol. 94: 377-384.

6. Carrasco, C. P., Rigden, R. C., Schaffner, R., Gerber, H., Neuhaus, V., Inumaru, S., Takamatsu, H., Bertoni, G., McCullough, K. C. and Summerfield, A. 2001. Porcine dendritic cells generated in vitro: morphological, phenotypic and functional properties. Immunology 104: 175-184.

7. Caux, C., Vanbervliet, B., Massacrier, C., Dezutter-Dambuyant, C., de Saint-Vis, B., Jacquet, C., Yoneda, K., Imamura, S., Schmitt, D. and Banchereau, J. 1996. CD34+ hematopoietic progenitors from human cord blood differentiate along two independent dendritic cell pathways in response to GM- 
CSF+TNF alpha. J. Exp. Med. 184: 695-706.

8. Chakraborty, A., Li L., Chakraborty, N. G. and Mukherji, B. 1999. Stimulatory and inhibitory maturation of human macrophage-derived dendritic cells. Pathobiology 67: 282-286.

9. de Baey, A., Mende, I., Riethmueller, G. and Baeuerle, P. A. 2001. Phenotype and function of human dendritic cells derived from M-DC8(+) monocytes. Eur. J. Immunol. 31: 1646-1655.

10. De Bakker, J. M., De Wit, A. W., Woelders, H., Ginsel, L. A. and Daems, W. T. 1985. On the origin of peritoneal resident macrophages. II. Recovery of the resident macrophage population in the peritoneal cavity and in the milky spots after peritoneal cell depletion. J. Submicrosc. Cytol. 17: 141-151.

11. Freeman, G. J., Gribben, J. G., Boussiotis, V. A., Ng, I. W., Restivo, Jr., V. A., Lombard, L. A., Gray, G. S. and Naddler, L. M. 1993. Cloning of B7-2; A CTLA-4 counter-receptor that costimulates human T cell proliferation. Science 262: 909-911.

12. Garlanda, C., Berthier, R., Garin, J., Stoppacciaro, A., Ruco, L., Vittet, D., Gulino, D., Matteucci, C., Mantovani, A., Vecchi, A. and Dejana, E. 1997. Characterization of MEC 14.7, a new monoclonal antibody recognizing mouse CD34: a useful reage for identifying and characterizing blood vessels and hematopoietic precursors. Eur. J. Cell. Biol. 73: 368-377.

13. Henri, S., Vremec, D., Kamath, A., Waithman, J., Williams, S., Benoist, C., Burnham, K., Saeland, S., Handman, E. and Shortman, K. 2001. The dendritic cell populations of mouse lymph nodes. J. Immunol. 167: 741-748.

14. Inaba, K., Inaba, M., Romani, N., Aya, H., Deguchi, M., Ikehara, S., Muramatsu, S. and Steinman, R.M. 1992a. Generation of large numbers of dendritic cells from mouse bone marrow cultures supplemented with granulocyte/macrophage colonystimulating factor. J. Exp. Med. 176: 1693-1702.

15. Inaba, K., Metlay, J. P., Crowley, M. T. and Steinman, R. M. 1990. Dendritic cells pulsed with protein antigens in vitro can prime antigen-specific, MHC-restricted T cells in situ. J. Exp. Med. 172: 631-640.

16. Inaba, K., Steinman, R. M., Witmer-Pack, M., Aya, H., Inaba, M., Sudo T., Wolpe, S. and Schuler, G. 1992b. Identification of proliferating dendritic cell precursors in mouse blood. J. Exp. Med. 175: 1157-1167.

17. Jiang, W., Swiggard, W. J., Heuffler, C., Peng, M., Mirza, A., Steinman, R. M. and Nusseinzweig, M. C. 1995. The receptor DEC-205 expressed by DC and thymic epithelial cells is involved in antigen processing. Nature (Lond.) 375: 151-155.

18. Kamath, A. T., Pooley, J., O'Keeffe, M. A., Vremec, D., Zhan, Y., Lew, A. M., D'Amico, A., Wu, L., Tough, D. F. and Shortman, K. 2000. The development, maturation, and turnover rate of mouse spleen dendritic cell populations. J. Immunol. 165: 6762-6770.

19. Kiertscher, S. M. and Roth, M. D. 1996. Human CD14+ leukocytes acquire the phenotype and function of antigen-presenting dendritic cells when cultured in GM-CSF and IL-4. J. Leukoc. Biol. 59: 208-218.

20. Kraal, G., Breel, M., Janse, M. and Bruin, G. 1986. Langerhans cells, veiled cells and interdigitating cells in the mouse recognized by a monoclonal antibody. J. Exp. Med. 163: 981-987.

21. Leenen, P. J., Melis, M., Slieker, W. A. and Van Ewijk, W. 1990. Murine macrophage precursor characterization. II. Monoclonal antibodies against macrophage precursor antigens. Eur. J. Immunol. 20: 27-34.

22. Lu, L., Hsieh, M., Oriss, T. B., Morel, P. A., Rao, A. S. and Thomson, A. W. 1995. Generation of DC from mouse spleen cell cultures in response to GM-CSF: Immunophenotypic and functional analyses. Immunology 84: 127-134.
23. Lutz, M. B., Kukutsch, N., Ogilvie, A. L. J., Ro $\beta$ ner, S., Koch, F., Romani, N. and Schuler, G. 1999. An advanced culture method for generating large quantities of highly pure dendritic cells from mouse bone marrow. J. Immunol. Methods 223: 7792.

24. Makala, L. H. C., Haverson, K., Stokes, C. R., Bailey, M. and Bland, P. W. 1998. Isolation and characterization of pig Peyer's patch dendritic cells. Vet. Immunol. Immunopathol. 61: 67-81.

25. Makala, L. H., Kamada, T., Nishikawa, Y., Nagasawa, H., Igarashi, I., Fujisaki, K., Suzuki, N., Mikami, T., Haverson, K., Bailey, M., Stokes, C. R. and Bland, P. W. 2000. Ontogeny of pig discrete Peyer's patches: distribution and morphometric analysis. Pathobiology 68: 275-282.

26. Makala, L.H.C. 1996. Isolation and characterization of pig Peyer's patch dendritic cells. Ph.D. Thesis. University of Bristol, Bristol, England, UK.

27. Makala, L.H.C., Nishikawa, Y., Kamada, T., Suzuki, H., Xuan, X., Igarashi, I. and Nagasawa, H. 2001. Comparison of the accessory activity of murine peritoneal cavity macrophage derived dendritic cells and peritoneal cavity macrophages in a mixed lymphocyte reaction. J. Vet. Med. Sci. 63: 1271-1277.

28. Manz, M. G., Traver, D., Miyamoto, T., Weissman, I. L. and Akashi, K. 2001. Dendritic cell potentials of early lymphoid and myeloid progenitors. Blood 97: 3333-3341.

29. Maraskovsky, E., Brasel, K., Teepe, M., Roux, E. R., Lyman, S. D., Shortman, K. and McKenna, H. J . 1996. Dramatic increase in the numbers of functionally mature dendritic cells in Flt3 ligand-treated mice: multiple dendritic cell subpopulations identified. J. Exp. Med. 184: 1953-1962.

30. Masurier, C., Pioche-Durieu, C., Colombo, B. M., Lacave, R., Lemoine, F. M., Klatzman, D. and Guigon, M. 1999. Immunophenotypical and functional heterogeneity of dendritic cells generated from murine bone marrow cultured with different cytokine combinations: implications for anti-tumoral cell therapy. Immunology 96: 569-577.

31. Metlay, J. P., Witmer-pack, M. D., Agger, R., Crowley, M. T., Lawless, D. and Steinman, R. M. 1990. The distinct leukocyte integrins of mouse spleen dendritic cells as identified with new hamster monoclonal antibodies. J. Exp. Med. 171: 1753-1771.

32. Mukherji, B., Chakraborty, N. G., Yamasaki, S., Okino, T., Yamase, H., Sporn, J. R., Kurtzman, S. K., Ergin, M. T., Ozols, J., Meehan, J. and Mauri, F. 1995. Induction of antigen-specific cytolytic $\mathrm{T}$ cells in situ in human melanoma by immunization with synthetic peptide-pulsed autologous antigen presenting cells. Proc. Natl. Acad. Sci. U.S.A. 92: 8078-8082.

33. Perez-Diez, A., Butterfield, L. H., Li, L., Chakraborty, N. G., Economou, J. S. and Mukherji, B. 1998. Generation of CD8+ and CD4+ T-cell response to dendritic cells genetically engineered to express the MART-1/Melan-A gene. Cancer Res. 58: 5305-5309.

34. Peters, J. H., Gieseler, R., Thiele, B. and Steinbach, F. 1996. Dendritic cells: from ontogenetic orphans to myelomonocytic descendants. Immunol. Today 17: 273-278.

35. Razi-Wolf, Z., Freeman, G. J., Galvin, F., Benaceraf, B., Nadler, L. and Reiser, H. 1992. Expression and function of the murine B7 antigen, the major costimulatory molecule expressed by peritoneal exudate cells. Proc. Natl. Acad. Sci. U.S.A. 89: 4210-4214.

36. Rezzani, R., Rodella, L., Zauli, G., Caimi, L. and Vitale, M. 1999. Mouse peritoneal cells as a reservoir of late dendritic cell progenitors. Br. J. Haematol. 104: 111-118.

37. Romani, N. and Schuller, G. 1989. Structure and functional relationships between epidermal Langerhans cells and den- 
dritic cells. Res. Immunol. 140: 895-898.

38. Schuler, G., Lutz, M., Bender, A., Thurner, B., Roder, C., Young, J. W. and Romani, N. 1998. A guide to the isolation and propagation of dendritic cells. p. 515. In: Dendritic Cells: Biology and Clinical Applications (Lotze, M. T. and Thomson, A. W. eds.), Academic Press, San Diego.

39. Springer, T., Galfre, G., Secher, D. S. and Milstein, C. 1979. Mac-1: a macrophage differentiation antigen identified by monoclonal antibody. Eur. J. Immunol. 9: 301-306.

40. Suzuki, Y., Yanagawa, H., Nishioka, Y., Nishimura, N., Takeuchi, E. and Sone, S. 2001. Efficient generation of dendritic cells from alveolar and pleural macrophages as well as blood monocytes in patients with lung cancer. Lung Cancer 34: 195-205.

41. Talmor, M., Mirza, A., Turley, S., Mellman, I., Hoffman, L. A. and Steinman, R.M. 1998. Generation of large numbers of immature and mature dendritic cells from rat bone marrow cultures. Eur. J. Immunol. 28: 811-817.

42. van Vugt, E., Arkema, J. M., Verdaasdonk, M. A., Beelen, R. H. and Kamperdijk, E. W. 1991. Morphological and functional characteristics of rat steady state peritoneal dendritic cells. Immunobiology 184: 14-24.

43. Vremec, D., Pooley, J., Hochrein, H., Wu, L. and Shortman, K.
2000. CD4 and CD8 expression by dendritic cell subtypes in mouse thymus and spleen. J. Immunol. 164: 2978-2986.

44. Vremec, D., Zorbas, M., Scollay, R., Saunders, D. J., Ardavin, C. J., Wu, L. and Shortman, K. 1992. The surface phenotype of dendritic cells purified from mouse thymus and spleen: Investigation of the CD8 expression by a subpopulation of dendritic cells. J. Exp. Med. 176: 47-58.

45. Wall, K. A., Lorber, M. I., Loken, M. R., McClatchey, S. and Fitch, F. W. 1983. Inhibition of proliferation of Mls- and Iareactive cloned $\mathrm{T}$ cells by a monoclonal antibody against a determinant shared by I-A and I-E. J. Immunol. 131: 10561064.

46. Wijffels, J. F., Hendrickx, R. J., Steenbergen, J. J., Eestermans, I. L. and Beelen, R. H. 1992. Milky spots in the mouse omentum may play an important role in the origin of peritoneal macrophages. Res. Immunol. 143: 401-409.

47. Williams, L. A., Egner, W. and Hart, D. N. 1994. Isolation and function of human dendritic cells. Int. Rev. Cytol. 153: 41-103.

48. Winzler, C., Rovere, P., Rescigno, M., Granucci, F., Penna, G., Adorini, L., Zimmermann, V. S., Davoust, J. and RicciardiCastagnoli, P. 1997. Maturation stages of mouse dendritic cells in growth factor-dependent long-term cultures. J. Exp. Med. 185: $317-328$ 